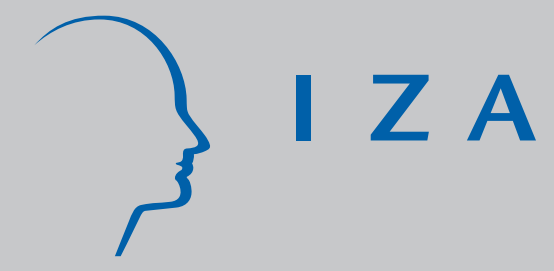

IZA DP No. 784

Low-Skilled Unemployment, Biased Technological Shocks and J ob Competition

Olivier Pierrard

Henri R. Sneessens

May 2003 


\title{
Low-Skilled Unemployment, Biased Technological Shocks and Job Competition
}

\author{
Olivier Pierrard \\ IRES, Catholic University of Louvain \\ Henri R. Sneessens \\ IRES, Catholic University of Louvain, \\ Catholic University of Lille and IZA Bonn
}

\author{
Discussion Paper No. 784 \\ May 2003
}

\author{
IZA \\ P.O. Box 7240 \\ D-53072 Bonn \\ Germany \\ Tel.: +49-228-3894-0 \\ Fax: +49-228-3894-210 \\ Email: iza@iza.org
}

This Discussion Paper is issued within the framework of IZA's research area Internationalization of Labor Markets. Any opinions expressed here are those of the author(s) and not those of the institute. Research disseminated by IZA may include views on policy, but the institute itself takes no institutional policy positions.

The Institute for the Study of Labor (IZA) in Bonn is a local and virtual international research center and a place of communication between science, politics and business. IZA is an independent, nonprofit limited liability company (Gesellschaft mit beschränkter Haftung) supported by the Deutsche Post AG. The center is associated with the University of Bonn and offers a stimulating research environment through its research networks, research support, and visitors and doctoral programs. IZA engages in (i) original and internationally competitive research in all fields of labor economics, (ii) development of policy concepts, and (iii) dissemination of research results and concepts to the interested public. The current research program deals with (1) mobility and flexibility of labor, (2) internationalization of labor markets, (3) welfare state and labor market, (4) labor markets in transition countries, (5) the future of labor, (6) evaluation of labor market policies and projects and (7) general labor economics.

IZA Discussion Papers often represent preliminary work and are circulated to encourage discussion. Citation of such a paper should account for its provisional character. A revised version may be available on the IZA website (www.iza.org) or directly from the author. 
IZA Discussion Paper No. 784

May 2003

\begin{abstract}
Low-Skilled Unemployment, Biased Technological Shocks and Job Competition*

The unemployment rise in EU countries has been particularly strong for low-skilled workers. This observation has often been explained in terms of biased technical change and relative wage rigidities. More attention has been paid recently to an alternative mechanism, the crowding-out of low-skilled workers by over-qualified workers. The objective of this paper is both methodological and empirical. We construct a dynamic general equilibrium model with two types of jobs and two types of workers and with search unemployment. The model is calibrated and simulated to examine the interactions between the "skill bias" and "crowdingout" mechanisms. When such interactions are accounted for, the model reproduces quite well the observed unemployment changes.
\end{abstract}

JEL Classification: E24, J21, J23

Keywords: skill bias, equilibrium search unemployment, ladder effect, crowding out, over-education

Corresponding author:

Henri Sneessens

IRES

Catholic University of Louvain

3, place Montesquieu

1348 Louvain-la-Neuve

Belgium

Tel.: +32 10473962

Fax: +3210473945

Email: sneessens@ires.ucl.ac.be

\footnotetext{
* Part of this work was done while visiting Cepremap, Paris. This research is part of a project financed by the Service des Etudes et de la Statistique (SES) of the Walloon Region, Belgium. We also benefited from the financial support of the PAI-UAP federal research programme P5/10/28.
} 


\section{Introduction}

The last decades have been characterized in many EU countries by a substantial increase in the average unemployment rate. Average unemployment rate statistics hide dramatic differences across skill groups. The increase has remained fairly small for high-skilled workers, while it is usually considerable for the least skilled groups. What caused this uneven development remains a debated issue. There is ample evidence suggesting that technological progress and other related factors (organizational change, capital-skill complementarity, etc...) may have substantially increased the relative demand for skilled workers (see for instance Autor et al. [5], Berman et al. [7], and Machin-Van Reenen [16]). We observed simultaneously a considerable increase in the relative supply of highly educated workers. This context suggest that two types of mechanisms may have contributed to the rise of low-skilled unemployment. The first one is the "skill bias technological change". It takes place when the net relative labor demand shift is unfavorable to low-skilled workers (see for instance Manacorda-Petrongolo [17]). If not compensated by relative wage adjustments, such a net demand change leads to larger unemployment rate differentials. Increasing attention has been paid recently to an alternative mechanism. Several recent empirical studies suggest that a significant and increasing proportion of low-skilled jobs are nowadays held by highly educated, over-qualified workers (see for instance Hartog [15]). There may be a variety of reasons why firms may choose or accept to hire high-skilled workers on low-skilled positions (imperfections of the matching process, productivity differences, etc...). Whatever these reasons, these empirical findings suggest a story quite different from the "skill bias technological change". The rise in low-skilled unemployment would not be the result of a net relative demand shift; it would rather be the consequence of the relative supply shift itself, which increased job competition and the "crowding-out" of the least skilled workers.

Both scenarios, skill bias change and crowding-out, are a priori plausible, and may indeed have taken place simultaneously. The objective of this paper is twofold. It first aims at contributing to a better understanding of the mechanisms at work in the two scenarios and their possible interactions. It also aims at providing a quantitative assessment of the respective contributions of "skill bias" and "crowding-out" phenomena to the overall low-skilled unemployment rise.

The specification of our model builds on earlier work on these issues. Mortensen-Pissarides [20] 
examine the consequences of a skilled-bias technological change in a model with matching frictions and a continuum of skill levels. The distribution of the labor force population over these skill levels is exogenously given. All firms are single job firms and produce the same goods. Different firms may however use different technologies. The distribution of firm types is endogenous: when opening a vacancy, a firm must specify the chosen technology and the corresponding minimal skill requirement; this decision is irreversible. A higher skill requirement is associated to a higher productivity level. The authors focus on the case where the labor market is perfectly segmented, so that there is no job competition across skill groups. Wages are determined by Nash bargaining. If the economic value of non-employment (unemployment benefit) is the same for all skill groups, the wage-productivity ratio will be higher for the less productive workers, implying a higher equilibrium unemployment rate on the corresponding segment of the labor market. A skill-biased technological change (defined as a mean-preserving increase in the spread of the distribution of labor productivity across workers) exacerbates these differences, by increasing the unemployment rate of less skilled workers and decreasing that of high-skilled workers. The aggregate equilibrium unemployment rate increases if the positive effect on less skilled unemployment dominates the negative effect on high skilled unemployment. The authors show that the magnitude of such effects depends on labor market institutions (job protection, unemployment benefits).

This type of model can be extended to include job competition effects provided one accepts the simplifying assumptions that the job destruction rate is exogenous, and there are only two skill groups and two types of jobs. In Gautier [13] and Albrecht-Vroman [3], each firm decides ex ante which type of job vacancy (complex or simple) to open (one could say alternatively that she chooses ex ante whether she will use a high- or a low-tech production technology). The proportion of each type of job is determined endogenously by the free entry conditions. Lowskilled workers can only perform simple tasks. High-skilled workers can carry out both complex and simple tasks; their productivity on simple tasks (for which they are "over-qualified") may be higher or lower than that of low-skilled workers. One main difference between the Gautier and the Albrecht-Vroman models comes from the representation of the matching process. Both models use matching functions à la Pissarides [23]. Albrecht-Vroman [3] represent the whole 
matching process by a single matching function and assume that a match is consummated if and only if the total surplus to be shared between the firm and the worker is non-negative ${ }^{1}$. Gautier [13] allows instead low-skilled workers to direct their search on simple jobs by introducing a different matching function for each type of job. Job competition is introduced by allowing high-skilled job seekers to search simultaneously on the complex and the simple job markets. When hired on a simple job, they may continue searching for a (better-paid) complex job.

These models provide important insights on the externalities associated to matching processes and on their implications for technological change and job competition mechanisms. In such setups, an exogenous increase in the proportion of high-skilled workers increases the number of complex jobs (high-tech firms) and thus induces an endogenous technological change ${ }^{2}$. It typically also increases the number of high-skilled workers on simple jobs. This crowding-out effect will in general increase low-skilled unemployment, except if high-skilled workers employed on simple jobs are sufficiently more productive than low-skilled workers. In that case, firms have an incentive to open more simple job vacancies; this creates more job opportunities for lowskilled workers as well (positive externality). Dolado et al. [11] and [12] use similar modelling approaches to investigate the potential impact of the increased proportion of highly educated workers and of job competition on low-skilled employment opportunities in Spain. Collard et al. [10] provide a first attempt to include this type of quantitative analysis in a dynamic general equilibrium setup with capital accumulation.

We will follow Collard et al. [10] and adopt an intertemporal general equilibrium framework similar to that of Andolfatto [4] and Merz [19], with endogenous capital and interest rate. We build on their work though by modelling labor market flows in a way similar to Gautier [13]. This approach allows us to introduce endogenous search intensities for high-skilled job seekers. High-skilled unemployed workers may search simultaneously on the complex and the simple job

\footnotetext{
${ }^{1}$ Marimon-Zilbotti [18] use a similar search-matching representation to examine the consequences of a biased technological shock. His model differs however from the one developed in this paper by its definition of workers and firms types (in terms of specific "talents" rather than skill levels). The productivity of a match is a negative function of the distance between the worker's and the firm's types (talent mismatch). A biased technological shock is represented in that setup by a stronger negative effect of talent mismatch on productivity.

${ }^{2}$ Similar mechanisms of endogenous technological change have been suggested by Acemoglu [1] and [2] and Beaudry and Green [6] for instance.
} 
markets (as in Gautier), but allocate their search time on each market so as to maximize expected utility. In this setup, lower employment and wage perspectives on the complex job market induce high-skilled unemployed workers to spend a larger fraction of their search time on the simple job market and thus lead to more crowding-out of low-skilled workers. The possibility of on-the-job search (continuing to search for a complex job while working on a simple job) reinforces such effects. On-the-job search intensity is again determined by expected utility maximization, with the opportunity cost of on-the-job search equal to the marginal utility of leisure.

As most authors in this literature, we will assume single job firms. The main motivation for this simplification is to keep a tractable representation of the wage bargaining process. We do not want to assume though that "high-tech" and "low-tech" firms (offering respectively complex and simple jobs) produce perfectly substitutable goods. This assumption would considerably simplify the representation of the production process. It would amount though to assuming that all workers are perfectly substitutable inputs differing only by their productivity level. We will follow a different route. Instead of assuming perfect substitutability, we will assume that high-tech and low-tech firms produce different intermediate goods, used as inputs in the production of final goods, in combination with capital. The final goods production function will be specified as a Cobb-Douglas function, as in standard dynamic macroeconomic models, extended here to distinguish two types of jobs and the corresponding intermediate goods. This specification implies a more realistic value of the elasticity of substitution between low- and high-skilled workers (substitution elasticity equal to one rather than infinity). It also implies that the marginal productivity of each type of job is decreasing. A biased technological change can in this setup be introduced as an exogenous change in the coefficients of the Cobb-Douglas function, implying an exogenous change in the relative demand for high-tech and low-tech intermediate goods, which in turn changes the relative demand for high- and low-skilled labor. This formulation is in line with econometric estimates of the technological bias as reported for instance in Manacorda-Petrongolo [17].

In many European countries, relative wages have remained remarkably stable despite huge unemployment rate differences across skill groups. These relative wage rigidities may be the result of legal restrictions like minimum wages, or be the results of agreements negotiated at the sec- 
toral or national levels. The standard assumption that all wages are determined by individual wage negotiations may thus imply much more relative wage flexibility than actually observed and may be quite misleading. To better understand the consequences of relative wage rigidities in the face of relative labor demand or relative labor supply changes, we will start from the assumption that wages paid on simple jobs are indexed on those paid on complex jobs, the latter being determined by the usual sharing rule. We compare the results obtained with this assumption to those obtained with the standard representation where all wages are freely negotiated.

The quantitative results are obtained by calibrating the parameters on the Belgian economy. Unemployment rate changes observed in Belgium over the last twenty five years have been close to those observed on average at the European level. The analysis of the Belgian case may thus provide insights on what happened in other countries as well. We evaluate the consequences of relative labor demand and relative labor supply changes over the period 1976-1996 and discuss the role of relative wage rigidities and of job competition. The model is calibrated to reproduce the situation observed in 1996. We next recalculate the equilibrium with all parameter values unchanged except two of them, the proportion of high-skilled workers in the total labor force and the complex goods Cobb-Douglas productivity coefficient, which are given their 1976 values. These two parameter changes suffice to generate unemployment rate changes quite similar to those observed between 1976 and 1996, suggesting that net relative labor demand shifts combined to relative wage rigidities are one of the main cause of the unemployment rise. This numerical exercice also shows that both "skill bias" and "crowding-out" mechanisms contribute to explain the observed changes. The two mechanisms should thus be seen as complementary rather than competing explanations of the rise in low-skilled unemployment. More insights on these mechanisms are obtained by simulating the effects of various types of shocks (aggregate technological shock, biased technological shock, wage shock, labor force composition changes, etc...) in various settings (flexible or rigid relative wages, job competition or perfect labor market segmentation).

The rest of the paper is organized as follows. Section 2 is devoted to the description of firms and households behaviors and market mechanisms (matching processes, wage bargaining). We 
next (section 3) calibrate the model and examine its properties through comparative static and dynamic simulation exercises. Section 4 concludes with a few remarks.

\section{The Model}

There are two broad categories of agents, households and firms. We assume a single representative household ${ }^{3}$. All members of the household supply inelastically one unit of labor. These consumer-workers may however have different skill levels (be low- or high-skilled workers); they may be employed or unemployed.

We distinguish three types of firms: two types of intermediate goods firms, producing respectively high- and low-tech intermediate goods with labor as sole input, and one representative final firm, combining capital and the two intermediate goods to produce an homogeneous final goods. The final goods can be either consumed or accumulated by the representative household. The production of high-tech intermediate goods involves complex tasks that can only be carried out by skilled labor. The production of low-tech intermediate goods is made of simpler tasks that can be carried out by both low- or high-skilled workers. There is thus a double heterogeneity as in Gautier [13], heterogeneity of jobs (simple vs complex) and heterogeneity of workers (high- and low-skilled).

There are three types of markets: labor, goods and capital. On the labor side, we distinguish the complex and the simple job markets. For each type of job, we assume an exogenous job destruction rate and represent the matching process by a standard matching function. Because they know that their application will always be turned down, low-skilled job seekers never apply for complex jobs. High-skilled unemployed workers may look for both types of jobs. High-skilled workers hired on a simple job may continue searching for a complex job (on-the-job search). All goods markets (the two intermediate goods and the final goods markets) are assumed to be perfectly competitive. The price of the final goods is normalized to one. On the capital market,

\footnotetext{
${ }^{3}$ This representative household formulation amounts to assuming that workers are perfectly insured against the unemployment risk. This simplification is common in the literature and reflects the current state of the art. Taking into account workers heterogeneity due to imperfect insurance markets would make the model totally untractable.
} 
the supply is determined by the stock of capital previously accumulated by the household. The interest rate adjusts to make the quantity demanded by the representative final firm equal to this predetermined capital stock.

Labor market flows are detailed in the next subsection. We next successively discuss firms and households behaviors, and the wage determination process.

\subsection{Labor Market Flows}

Let $N_{t}^{c}$ and $N_{t}^{s}$ represent the total number of complex and simple jobs respectively. Simple jobs can be occupied by high- $\left(N_{t}^{s h}\right)$ or low-skilled $\left(N_{t}^{s l}\right)$ workers, so that $N_{t}^{s}=N_{t}^{s h}+N_{t}^{s l}$. Normalizing the total labor force to one and denoting $\alpha$ the (exogenous) proportion of highskilled workers yields the following accounting identities:

$$
N_{t}^{c}+N_{t}^{s h}+U_{t}^{h}=\alpha, \quad \text { and } \quad N_{t}^{s l}+U_{t}^{l}=1-\alpha,
$$

where $U_{t}^{h}$ and $U_{t}^{l}$ denote the number of high- and low-skilled unemployed job-seekers respectively. Let the number of complex and simple job matches be denoted by $M_{t}^{c}$ and $M_{t}^{s}$ respectively. We assume that the number of such matches is a function of the number of corresponding job vacancies $\left(V_{t}^{c}\right.$ and $V_{t}^{s}$ ) and effective job seekers (number of job seekers corrected by search efficiencies), that is, we use the following two matching functions:

$$
M_{t}^{c}=M^{c}\left(V_{t}^{c}, s c_{t} U_{t}^{h}+s o_{t} N_{t}^{s h}\right) \quad \text { and } \quad M_{t}^{s}=M^{s}\left(V_{t}^{s}, s s_{t} U_{t}^{h}+U_{t}^{l}\right) .
$$

where $s c_{t}, s s_{t}$ and $s o_{t}$ represent search efficiencies; the search efficiency of the low-skilled worker on the simple job market is normalized to one. Both matching functions are assumed to be linear homogeneous.

We denote labor market tensions by $\theta_{t}^{c}$ and $\theta_{t}^{s}$ respectively, where:

$$
\theta_{t}^{c} \equiv \frac{V_{t}^{c}}{s c_{t} U_{t}^{h}+s o_{t} N_{t}^{s h}} \quad \text { and } \quad \theta_{t}^{s} \equiv \frac{V_{t}^{s}}{s s_{t} U_{t}^{h}+U_{t}^{l}}
$$

With linear homogeneous matching functions, the probabilities of finding a complex or a simple job per unit of search intensity can be respectively written as follows:

$$
p_{t}^{c}=\frac{M_{t}^{c}}{s c_{t} U_{t}^{h}+s o_{t} N_{t}^{s h}}=p^{c}\left(\theta_{t}^{c}\right) \quad \text { and } \quad p_{t}^{s}=\frac{M_{t}^{s}}{s s_{t} U_{t}^{h}+U_{t}^{l}}=p^{s}\left(\theta_{t}^{s}\right) .
$$




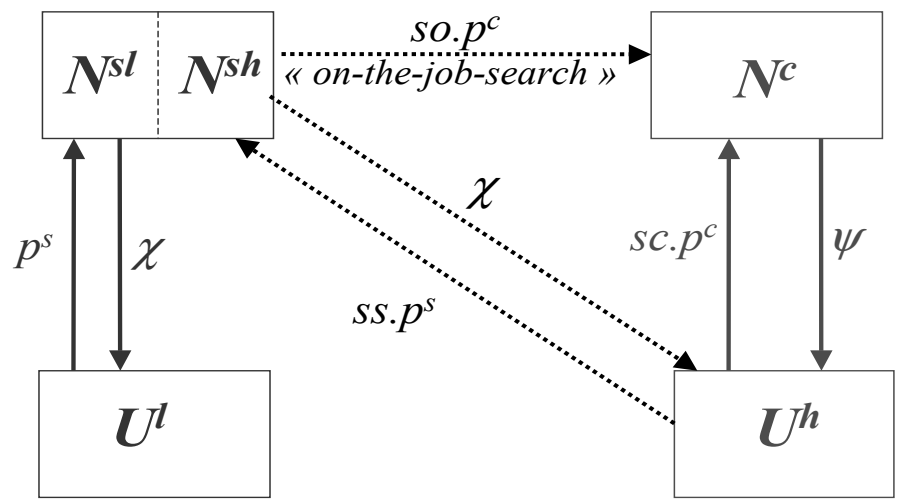

Figure 1: Labor market flows and transition probabilities

The probabilities of filling a complex and a simple job vacancy are similarly given by:

$$
q_{t}^{c}=\frac{M_{t}^{c}}{V_{t}^{c}}=q^{c}\left(\frac{1}{\theta_{t}^{c}}\right) \quad \text { and } \quad q_{t}^{s}=\frac{M_{t}^{s}}{V_{t}^{s}}=q^{s}\left(\frac{1}{\theta_{t}^{s}}\right) .
$$

The probability that a simple job is filled is the sum of the probabilities of hiring a high-skilled worker and a low-skilled worker:

$$
q_{t}^{s h}=\frac{s s_{t} U_{t}^{h}}{s s_{t} U_{t}^{h}+U_{t}^{l}} q_{t}^{s} \quad \text { and } \quad q_{t}^{s l}=\frac{U_{t}^{l}}{s s_{t} U_{t}^{h}+U_{t}^{l}} q_{t}^{s} .
$$

Finally, we assume two exogenous job destruction rates $\psi$ (for the complex jobs) and $\chi$ (for the simple jobs), implying for each type of job and worker the following employment dynamics (in terms of vacancies and job-seekers' search effort respectively):

$$
\begin{aligned}
N_{t+1}^{c} & =(1-\psi) N_{t}^{c}+q_{t}^{c} V_{t}^{c}, \\
& =(1-\psi) N_{t}^{c}+p_{t}^{c}\left[s c_{t} U_{t}^{h}+s o_{t} N_{t}^{s h}\right] . \\
N_{t+1}^{s h} & =\left(1-\chi-s o_{t} p_{t}^{c}\right) N_{t}^{s h}+q_{t}^{s h} V_{t}^{s}, \\
& =\left(1-\chi-s o_{t} p_{t}^{c}\right) N_{t}^{s h}+p_{t}^{s} s s_{t} U_{t}^{h} . \\
N_{t+1}^{s l} & =(1-\chi) N_{t}^{s l}+q_{t}^{s l} V_{t}^{s}, \\
& =(1-\chi) N_{t}^{s l}+p_{t}^{s} U_{t}^{l} .
\end{aligned}
$$

Figure 1 summarizes these labor market flows and transition probabilities. Armed with these definitions and notations, we can now describe firms and household behaviors. 


\subsection{The Intermediate Goods Firms}

We distinguish "high-tech" or "low-tech" intermediate goods firms. All are assumed to be single job firms. High-tech (resp. low-tech) firms offer complex (resp. simple) jobs.

The asset values of a complex vacancy and of a filled complex job will be denoted $W^{V C}$ and $W^{F C}$ respectively. Given the transition probabilities defined in the previous subsection, these values are determined by:

$$
\begin{aligned}
& W_{t}^{V C}=-a+\mathrm{E}_{t}\left[q_{t}^{c} \frac{W_{t+1}^{F C}}{1+r_{t+1}}+\left(1-q_{t}^{c}\right) \frac{W_{t+1}^{V C}}{1+r_{t+1}}\right], \\
& W_{t}^{F C}=c_{t}^{c} y^{c}-w_{t}^{c}+\mathrm{E}_{t}\left[(1-\psi) \frac{W_{t+1}^{F C}}{1+r_{t+1}}+\psi \frac{W_{t+1}^{V C}}{1+r_{t+1}}\right],
\end{aligned}
$$

where $a$ denotes the cost of keeping the complex vacancy opened, while $c_{t}^{c}$ stands for the market price of a complex (high-tech) goods and $w_{t}^{c}$ is the wage paid to the high-skilled worker. The productivity of the latter is equal to $y^{c}$.

Asset values for simple vacancies and jobs take more complicated forms because these positions may be held by low- or by high-skilled workers. Because of high-skilled workers search behavior, high- and low-skilled workers have different hiring and exit probabilities. They also have different productivity levels. The productivity of a high-skilled worker on a simple job is equal to $y^{s}$; the productivity of a low-skilled worker is assumed to be a fraction $\nu$ of the latter ${ }^{4}$. Let $W^{V S}$ denote the asset value of a simple vacancy, while $W^{F S H}$ and $W^{F S L}$ denote the asset values of a filled simple job held by a high-skilled and a low-skilled worker respectively. These asset values are determined by the following dynamic equations:

$$
\begin{aligned}
W_{t}^{V S} & =-b+\mathrm{E}_{t}\left[q_{t}^{s h} \frac{W_{t+1}^{F S H}}{1+r_{t+1}}+q_{t}^{s l} \frac{W_{t+1}^{F S L}}{1+r_{t+1}}+\left(1-q_{t}^{s h}-q_{t}^{s l}\right) \frac{W_{t+1}^{V S}}{1+r_{t+1}}\right], \\
W_{t}^{F S H} & =c_{t}^{s} y^{s}-w_{t}^{s h}+\mathrm{E}_{t}\left[\left(1-\chi-p_{t}^{c} s o_{t}\right) \frac{W_{t+1}^{F S H}}{1+r_{t+1}}+\left(\chi+p_{t}^{c} s o_{t}\right) \frac{W_{t+1}^{V S}}{1+r_{t+1}}\right], \\
W_{t}^{F S L} & =\nu c_{t}^{s} y^{s}-w_{t}^{s l}+\mathrm{E}_{t}\left[(1-\chi) \frac{W_{t+1}^{F S L}}{1+r_{t+1}}+\chi \frac{W_{t+1}^{V S}}{1+r_{t+1}}\right],
\end{aligned}
$$

where $b$ denotes the cost of keeping the simple vacancy opened, while $c_{t}^{s}$ stands for the market price of a simple (low-tech) goods. The wages paid by low-tech firms to high- or low-skilled

\footnotetext{
${ }^{4}$ A priori, $\nu$ could be lower or higher than 1 . In other words, a low-skilled could be less or more productive than a high-skilled on a simple job.
} 
workers are denoted $w_{t}^{s h}$ and $w_{t}^{s l}$ respectively.

Finally, the number of high- or low-tech firms is determined by the usual free entry conditions $\left(W_{t}^{V C}=W_{t}^{V S}=0\right)$.

\subsection{The Representative Final Firm}

We assume a representative final firm. Producing the final goods $y_{t}$ requires three types of inputs: capital $K_{t}$, high-tech (complex) intermediate goods $Q_{t}^{c}$, low-tech (simple) intermediate goods $Q_{t}^{s}$. The demand for these three inputs is determined by profit maximization:

$$
\max _{K_{t}, Q_{t}^{c}, Q_{t}^{s}} F\left(K_{t}, Q_{t}^{c}, Q_{t}^{s}\right)-c_{t}^{c} Q_{t}^{c}-c_{t}^{s} Q_{t}^{s}-\left(r_{t}+\delta\right) K_{t},
$$

where $F($.$) is a linear homogeneous production function, r_{t}$ is the net interest rate paid to capital owners and $\delta$ an exogenous capital depreciation rate. The first-order optimality conditions can then be written as follows:

$$
F_{K_{t}}=r_{t}+\delta ; \quad F_{Q_{t}^{c}}=c_{t}^{c} ; \quad F_{Q_{t}^{s}}=c_{t}^{s} .
$$

where $F_{X_{t}}$ is the first-partial derivative of $F($.$) with respect to X_{t}$. Because the intermediate goods prices $c_{t}^{c}$ and $c_{t}^{s}$ are market-clearing prices, we also have:

$$
Q_{t}^{c}=y^{c} N_{t}^{c} ; \quad Q_{t}^{s}=y^{s}\left(N_{t}^{s h}+\nu N_{t}^{s l}\right)
$$

\subsection{The Representative Household}

Let the representative household's value function be represented by the following function of the household's four state variables ${ }^{5}$ :

$$
W_{t}^{H}=W^{H}\left(K_{t}, N_{t}^{c}, N_{t}^{s h}, N_{t}^{s l}\right)
$$

All members of the household supply inelastically one unit of labor. The decision variables of the household are the consumption level $C_{t}$ and the search efforts of job seekers. We assume that low-skilled unemployed workers devote all their time searching on the simple job market.

\footnotetext{
${ }^{5}$ As mentioned before, assuming a representative household amounts to assuming perfect unemployment insurance, a usual assumption in this type of models.
} 
Their search efficiency is normalized to one. High-skilled unemployed workers allocate their total search time (normalized to one) between the simple and the complex job markets. Their search efficiency on the complex (resp. simple) job market, denoted $s c_{t}$ (resp. $s s_{t}$ ), is an increasing and concave function of the search time devoted to that market (eut and $\left(1-e u_{t}\right)$ respectively). High-skilled workers employed on a simple job may spend a fraction $e o_{t}$ of their leisure time searching for a better paid complex job. Their on-the-job search efficiency $s o_{t}$ is an increasing concave function of $e o_{t}$.

With these definitions and notations, the household optimization programme can be written in the form of the following Bellmann equation:

$$
W_{t}^{H}=\max _{C_{t}, e u_{t}, e o t}\left\{\mathcal{U}\left(C_{t}\right)-\mathcal{D}\left(e o_{t}\right) N_{t}^{s h}+\beta \mathrm{E}_{t}\left[W_{t+1}^{H}\right]\right\}
$$

$\mathcal{U}($.$) is an increasing and concave utility function, \mathcal{D}($.$) is an increasing and convex disutility$ function, $\beta$ is a subjective discount factor. The optimization is subject to constraints (1), (7-b), (8-b), (9-b) and to the flow budget constraint (income = expenditure):

$$
\begin{aligned}
w_{t}^{c} N_{t}^{c} & +w_{t}^{s h} N_{t}^{s h}+w_{t}^{s l} N_{t}^{s l}+w_{t}^{u}\left(U_{t}^{h}+U_{t}^{l}\right)+\left(r_{t}+\delta\right) K_{t}+\Pi_{t} \\
& =K_{t+1}-(1-\delta) K_{t}+C_{t}+T_{t}
\end{aligned}
$$

where $w_{t}^{u}$ stands for the benefits received by an unemployed worker, $\Pi_{t}$ stands for the profits (value added net of labor and vacancy costs) redistributed by intermediate firms and $T_{t}$ stands for the (lump sum) taxes levied to finance the unemployment benefits. The first-order optimality conditions can then be written as follows:

$$
\begin{aligned}
\mathcal{U}_{C_{t}} & =\beta \mathrm{E}_{t}\left[\left(1+r_{t+1}\right) \mathcal{U}_{C_{t+1}}\right] \\
0 & =\mathrm{E}_{t}\left[p_{t}^{c} s c_{e u_{t}} W_{N_{t+1}^{c}}^{H}-p_{t}^{s} s s_{1-e u_{t}} W_{N_{t+1}^{s h}}^{H}\right], \\
\mathcal{D}_{e o t} & =\beta p_{t}^{c} s o_{e o t} \mathrm{E}_{t}\left[W_{N_{t+1}^{c}}^{H}-W_{N_{t+1}^{s h}}^{H}\right] .
\end{aligned}
$$


From the envelope theorem, we obtain the following additional dynamic relationships:

$$
\begin{aligned}
W_{N_{t}^{c}}^{H}= & \mathcal{U}_{C_{t}}\left(w_{t}^{c}-w_{t}^{u}\right) \\
& +\beta\left(1-\psi-s c_{t} p_{t}^{c}\right) \mathrm{E}_{t}\left[W_{N_{t+1}^{c}}^{H}\right]-\beta s s_{t} p_{t}^{s} \mathrm{E}_{t}\left[W_{N_{t+1}^{s h}}^{H}\right], \\
W_{N_{t}^{s h}}^{H}= & \mathcal{U}_{C_{t}}\left(w_{t}^{s}-w_{t}^{u}\right)-\mathcal{D}\left(e o_{t}\right) \\
& +\beta\left(s o_{t}-s c_{t}\right) p_{t}^{c} \mathrm{E}_{t}\left[W_{N_{t+1}^{c}}^{H}\right]+\beta\left(1-\chi-s o_{t} p_{t}^{c}-s s_{t} p_{t}^{s}\right) \mathrm{E}_{t}\left[W_{N_{t+1}^{s h}}^{H}\right], \\
W_{N_{t}^{s l}}^{H}= & \mathcal{U}_{C_{t}}\left(w_{t}^{s}-w_{t}^{u}\right)+\beta\left(1-\chi-p_{t}^{s}\right) \mathrm{E}_{t}\left[W_{N_{t+1}^{s l}}^{H}\right] .
\end{aligned}
$$

\subsection{Wage Determination}

We assume that the wage $w_{t}^{c}$ paid to a worker on a complex job is renegotiated every time with the intermediate firm. The bargained wage is determined by the maximization of the Nash product (see for instance Cahuc-Zylberberg [8]):

$$
\max _{w_{t}^{c}}\left(\frac{W_{N_{t}^{c}}^{H}}{\mathcal{U}_{C_{t}}}\right)^{\eta^{c}}\left(W_{t}^{F C}-W_{t}^{V C}\right)^{\left(1-\eta^{c}\right)},
$$

where $\eta^{c}$ represents the high-skilled worker's bargaining power. The first order condition gives, using the free entry condition:

$$
W_{N_{t}^{c}}^{H}=\eta^{c}\left(W_{N_{t}^{c}}^{H}+\mathcal{U}_{C_{t}} W_{t}^{F C}\right)
$$

Concerning wages paid on simple jobs, we contrast two cases. We first assume that this wage is identical for both low- and-high-skilled workers and is indexed on the complex job wage $w_{t}^{c}$. More precisely:

$$
w_{t}^{s l}=w_{t}^{s h}=\gamma w_{t}^{c}
$$

This amounts to assuming a rigid, exogenous relative wage $(\gamma)$ between simple and complex jobs, resulting for instance from centralized labor market regulations and institutions. This assumption is motivated by the observation that the relative wage of low-skilled workers has in many countries remained quite stable over the last decades ${ }^{6}$.

\footnotetext{
${ }^{6}$ In OECD [21], data (from 1979 to 1995) about the distribution of earnings (D9/D5 (ratio of the upper earnings limit of the ninth decile of workers to the upper limit of the fifth decile) and D5/D1) are provided for eleven EU countries. For all these countries (except in UK), these ratios remain fairly stable all over the period studied.
} 
In order to better evaluate the implications of relative wage rigidities, we contrast the results obtained under the rigid relative wage assumption to those obtained under an assumption of individual wage bargaining similar to that taking place for complex jobs. More formally, we will contrast the first specification with the alternative one where the wage $w_{t}^{s l}$ (resp. $w_{t}^{s h}$ ) paid to a low-skilled (resp. high-skilled) worker employed on a simple job is determined by the maximization of the Nash product. The wage $w_{t}^{s h}$ paid to high-skilled workers on simple jobs is similarly defined. The bargained wages $w_{t}^{s l}$ and $w_{t}^{s h}$ then solve:

$$
\begin{aligned}
W_{N_{t}^{s l}}^{H} & =\eta^{s}\left(W_{N_{t}^{s l}}^{H}+\mathcal{U}_{C_{t}} W_{t}^{F S L}\right), \\
W_{N_{t}^{s h}}^{H} & =\eta^{s}\left(W_{N_{t}^{s h}}^{H}+\mathcal{U}_{C_{t}} W_{t}^{F S H}\right),
\end{aligned}
$$

where $\eta^{s}$ represents the worker's bargaining power. The wages $w_{t}^{s l}$ and $w_{t}^{s h}$ so obtained will in general differ, because low-and high-skilled workers have different productivity levels $(\nu \neq 1)$ and exit probabilities (as a result of on-the-job-search by high-skilled workers).

Finally, the unemployment benefit $w_{t}^{u}$ is assumed to be the same for all workers. It is defined as a fraction $w^{u}$ of the average wage ${ }^{7}$ :

$$
w_{t}^{u}=w^{u} \frac{N_{t}^{c} w_{t}^{c}+N_{t}^{s h} w_{t}^{s h}+N_{t}^{s l} w_{t}^{s l}}{N_{t}^{c}+N_{t}^{s h}+N_{t}^{s l}}
$$

\section{Model Calibration and Simulations}

In this section we calibrate the model and use deterministic simulation exercises to illustrate the properties of the model and gain insights on the effects of various types of shocks. The focus is on search intensities, unemployment rate differences (across skill groups) and crowding-out.

\footnotetext{
${ }^{7}$ This is more realistic than assuming a replacement ratio identical for all workers. In most countries, unemployment benefit are capped, at least after some delay.
} 


\subsection{Calibration}

We use the following specific functions:

$$
\begin{aligned}
M_{t}^{s} & =m_{0}^{s}\left(V_{t}^{s}\right)^{\lambda^{s}}\left(s s_{t} U_{t}^{h}+U_{t}^{l}\right)^{1-\lambda^{s}} & & \text { matching function (simple jobs) } \\
M_{t}^{c} & =m_{0}^{c}\left(V_{t}^{c}\right)^{\lambda^{c}}\left(s c_{t} U_{t}^{h}+s o_{t} N_{t}^{s h}\right)^{1-\lambda^{c}} & & \text { matching function (complex jobs) } \\
F_{t} & =e\left(K_{t}\right)^{\theta}\left(N_{t}^{c}\right)^{\mu}\left(N_{t}^{s h}+\nu N_{t}^{s l}\right)^{1-\theta-\mu} & & \text { production function } \\
\mathcal{U}_{t} & =\ln C_{t} & & \text { instantaneous utility function } \\
\mathcal{D}_{t} & =\tau e o_{t} & & \text { instantaneous disutility function } \\
s c_{t} & =\phi_{0}^{s c}+\phi_{1}^{s c} \sqrt{e u_{t}} & & \text { search efficiency (i) } \\
s s_{t} & =\phi_{0}^{s s}+\phi_{1}^{s s} \sqrt{1-e u_{t}} & & \text { search efficiency (ii) } \\
s o_{t} & =\phi_{0}^{s o}+\phi_{1}^{s o} \sqrt{e o_{t}} & & \text { search efficiency (iii) }
\end{aligned}
$$

The matching function on each job market (simple and complex) is represented by the usual Cobb-Douglas specification with constant returns to scale. We follow Manacorda and Petrongolo [17] and use also a constant returns-to-scale Cobb-Douglas function with three inputs to represent the technological constraints faced by the representative final firm. A biased technological change favorable to high-skilled labor is in this setup represented by an increase in the value of parameter $\mu$. A larger value of $\mu$ increases (resp. decreases) the elasticity of output with respect to complex (resp. simple) goods. As in many RBC models, we represent the instantaneous utility of consumption by the logarithm of consumption expenditures. All workers supply inelastically one unit of their time. If unemployed, this time is entirely devoted to search. We still have to describe how much leisure time high-skilled workers employed on simple jobs will devote to on-the-job search, and how much of their total search time high-skilled unemployed workers will devote on the simple (rather than complex) job market. The disutility of devoting some of its leisure time to on-the-job search is assumed to be linear. We represent the relationship between search time and search efficiency by a concave function (more precisely, search efficiency is a linear function of the square root of search time).

The numerical values given to the parameters of these functions are reported in table 1 . One period of time corresponds to one quarter. As in most RBC models, the psychological discount factor $(\beta)$ is set to 0.99 , implying a steady state real interest rate of 0.01 (real interest rate of $4 \%$ 
per annum). Parameter $\theta$ is the elasticity of output with respect to capital, and coincides the capital share of total income. We set it at the standard value 0.33 . The depreciation rate $\delta$ is set to 0.025 and implies a steady state capital-output ratio equal to 9 . The labour productivities $y^{c}$ and $y^{s}$ in the complex and simple intermediate goods firms are (without loss of generality) normalized to 1 . The relative efficiency of a low-skilled worker on a simple job $(\nu)$ is set at 0.8. This value is such that, although the low-skilled worker's productivity is large enough to generate a positive surplus, the intermediate goods firm would prefer to fill a simple job vacancy with a high-skilled worker (more formally $\nu=0.8$ implies $W^{F S H}>W^{F S L}>0$ ). This seems a natural assumption in a model focusing on job competition. This particular choice has however little impact on the properties of the model (see below). We assume that recruiting costs are higher for complex jobs $(a>b)$. Our calibration of $a$ and $b$ implies that total vacancy costs represent $3.7 \%$ of total labor costs, $2.5 \%$ of output.

\begin{tabular}{|c|c|c|c|}
\hline Symbol & Value & Symbol & Value \\
\hline \multicolumn{4}{|c|}{ Labor force composition } \\
\hline \multicolumn{4}{|c|}{0.67} \\
\hline \multicolumn{4}{|c|}{ Job destruction rates } \\
\hline$\psi$ & 0.025 & $\chi$ & 0.05 \\
\hline \multicolumn{4}{|c|}{ Matching functions } \\
\hline$m_{0}^{c}$ & 0.40 & $\lambda^{c}$ & 0.40 \\
\hline$m_{0}^{s}$ & 0.30 & $\lambda^{s}$ & 0.40 \\
\hline \multicolumn{4}{|c|}{ Production functions } \\
\hline$\theta$ & 0.33 & $\mu$ & 0.51 \\
\hline$e$ & 1.00 & $\nu$ & 0.80 \\
\hline$y^{c}$ & 1.00 & $y^{s}$ & 1.00 \\
\hline \multicolumn{4}{|c|}{ Instantaneous disutility of on-the-job search } \\
\hline$\tau$ & 0.41 & & \\
\hline \multicolumn{4}{|c|}{ Search efficiencies } \\
\hline$\phi_{0}^{s c}$ & 0.10 & $\phi_{1}^{s c}$ & 0.50 \\
\hline$\phi_{0}^{s s}$ & 0.40 & $\phi_{1}^{s s}$ & 1.00 \\
\hline$\phi_{0}^{s o}$ & 0.60 & $\phi_{1}^{s o}$ & 0.50 \\
\hline \multicolumn{4}{|c|}{ Vacancy costs } \\
\hline$a$ & 0.90 & $b$ & 0.26 \\
\hline \multicolumn{4}{|c|}{ Wages determination } \\
\hline$\eta^{c}$ & 0.60 & $\eta^{s}$ & 0.77 \\
\hline$w^{u}$ & 0.34 & $\gamma$ & $2 / 3$ \\
\hline \multicolumn{4}{|c|}{ Psychological discount and capital depreciation } \\
\hline$\beta$ & 0.99 & $\delta$ & 0.025 \\
\hline
\end{tabular}

Table 1: Numerical parameter values 
Most of the remaining parameters are calibrated on Belgian data. The reference period is the second half of the nineties (mainly 1995-97), a period during which the Belgian economy was neither in a recession nor in a boom. The worker's skill level is defined in terms of educational attainment; the proportion $\alpha$ of high-skilled workers is defined as the proportion of workers with a education level equal to a upper-secondary degree or more. We set $\alpha$ and $\mu$ (the elasticity of output with respect to complex jobs) at values corresponding to the 1995-96 values obtained by Sneessens and Shadman [24] for Belgium $(\alpha=0.67, \mu=0.51)$. The elasticity of job matches with respect to vacancies $(\lambda)$ is usually estimated to be in between 0.4 and 0.6. Using 1997 Belgian data, Van der Linden and Dor [26] estimate it at 0.4 (without distinction between highand low-skilled jobs) and we therefore follow them by setting $\lambda^{c}=\lambda^{s}=0.4$, for both complex and simple jobs.

The parameter determining the worker's share of a match surplus is usually set at the same value as the coefficient of unemployment in the matching function (see for instance Merz [19] and Andolfatto [4] $)^{8}$. We follow this practice in choosing the value of $\eta^{c}$ (the wage rule on the complex job market), although in our setup it will not imply that the decentralized economy yields a social optimum. As discussed and motivated in section 2.5, we will assume that wages on the simple job market are a constant fraction of the complex wage. This ratio of simple to complex wages $(\gamma)$ is fixed at $2 / 3$. This value is close to the D1/D9 value reported by the OECD [21] for Belgium, and coincides with the relative mean gross wage of the $33 \%$ lowest-paid workers (see ONSS [22]). In order to evaluate the role of this relative wage rigidity in determining the economy's responses to shocks, we want compare the results obtained under this assumption with those obtained under the assumption of bargained simple wages, with share parameter $\eta^{s}$. The latter parameter is set at a value such that the initial (reference) steady state values are similar in both modelling strategies ${ }^{9}$. This implies $\eta^{s}=0.77$. The value of the average replacement ratio $w^{u}$ is set at 0.34 , the value obtained by Van der Linden and Dor [26] for Belgium in 1997. The same authors estimate a lower bound for the job destruction rate (or transition rate from employment to unemployment) equal to 0.013 (monthly data). Simple jobs

\footnotetext{
${ }^{8}$ Their motivation is the so-called Hosios-Pissarides condition: in models like Merz's or Andolfatto's, this sharing rule implies that the decentralized economy gives the same outcomes as the social planner problem.

${ }^{9}$ They cannot be exactly identical because in the bargained wage case $w^{s h}$ and $w^{s l}$ will in general be different.
} 
being typically more precarious than complex jobs, we impose the complex jobs destruction rate $\psi$ to be lower than the simple jobs destruction rate $\chi$. Using the Van der Linden and Dor [26] lower-bound estimate as a reference, we set the complex and simple job destruction rates at $\psi=0.025$ and $\chi=0.05$ respectively (quarterly data).

We still have to fix the following nine parameters: the two matching efficiencies $m_{o}^{c}$ and $m_{o}^{s}$, the six parameters of the search efficiency functions and the disutility parameter $\tau$. The three slope parameters in the search efficiency functions $\left(\phi_{1}^{x}, x \epsilon\{s c, s s, s o\}\right)$ play an important role in determining the effects of shocks. We want these slopes to be as large as possible without generating negative values for the job asset values $W_{t}^{F S H}, W_{N_{t}^{s c}}^{H}$ and $W_{N_{t}^{s h}}^{H}$ (see equations (13) and (24)-(25)). We are then left with six parameters. We choose their values so as to satisfy the following six steady state conditions: low- and high-skilled unemployment rates around 0.20 and 0.07 respectively (values obtained from Sneessens and Shadman [24] for Belgium, updated for 1995-96); probabilities to find a complex job and a simple job equal to $p^{c}=0.40$ and $p^{s}=0.20$ respectively (estimates based on Cockx and Dejemeppe [9] for the early nineties) ${ }^{10}$; and equal probabilities (around 0.50) to fill complex or simple vacancies $\left(q^{c}\right.$ and $q^{s}$ respectively). These latter values are based on Delmotte et al. [25]. They report that, in 2000, 52\% of the total vacancies were easily filled (within 3 months), $25 \%$ were filled with difficulty (vacancies open more than 3 months) and 33\% were never filled. Carefully examining which types of jobs are most easily filled does not suggest any difference between complex jobs and simple jobs.

A result of these calibration exercise is that the proportion of high-skilled workers on simple jobs must be around $8 \%$ (see table 2). This "crowding-out" effect may look rather small, if compared to the estimates reported in Delmotte et al. [25]. Delmotte et al. [25] used survey questionnaires with business firms to compare the skill requirements of job vacancies and the skill characteristics of the workers who filled these vacancies. A worker is considered to be overeducated when its education level is superior to that demanded by the firm when opening

\footnotetext{
${ }^{10}$ The probability that a worker finds a job during the first three months of unemployment is estimated at 0.64 for a worker with some post-secondary education, 0.39 with upper secondary education, 0.30 with lower secondary education and 0.28 with primary education or no education. The values kept for $p^{c}$ and $p^{s}$ take into account both our definition of the two skill groups and the fact that first trimester exit probabilities should be regarded as upper bounds.
} 
the vacancy. Delmotte et al. [25] obtain that in 2000, $24 \%$ of all hired workers were overeducated. This figure may however overestimate the true number of overeducated workers if for instance the education level indicated by firm when opening a vacancy is meant to give a lower bound rather than a strict requirement. Hartog [15], collecting empirical results from various studies, reports estimates ranging from 10 to $30 \%$ in EU countries during the first half of the nineties. Our own figure is just slightly below the low end of this range. If we keep in mind that distinguishing only two skill categories (rather than three or more) will mechanically and maybe drastically reduce the number of "overeducated" workers, the figure that we obtain with our calibrated model may seem realistic enough.

\subsection{Responses to shocks}

To better understand the properties of the model, we use numerical simulations and examine the consequences of specific shocks. We focus here on the model with rigid relative wages. The results of these comparative static exercises are summarized in table 2. The first row of the table reports the stationary state values of the main endogenous variables in the reference scenario. The other rows report the effects of the shocks. The effect is measured by the percentage deviation (percentage point difference when the initial variable is already expressed in percent) with respect to the value in the reference scenario. We consider seven types of shocks: labor force composition changes, four types of productivity shocks and two types of wage shocks. We briefly comment each exercise, starting with the aggregate productivity shock.

At unchanged unemployment benefits and vacancy costs, a positive aggregate productivity shock $(\Delta e>0$, equal to $3 \%$ in table 2$)$ stimulates the demand for all types of inputs. This overall stimulus leaves high-skilled workers' search behaviors almost unchanged. Crowding-out turns out to be only very slightly contra-cyclical, a result that is compatible with the empirical results obtained by Gautier et al. [14]. There is a strong increase in capital accumulation and output, and simultaneously a strong increase in wages (hence a weak employment effect). These results do not depend on the assumption that high-skilled workers employed on simple jobs are more productive than low-skilled workers. They are quite similar if we assume that wages paid on simple jobs are negotiated rather than indexed on complex wages. 


\begin{tabular}{|c|c|c|c|c|c|c|c|c|}
\hline & $e u$ & $e o$ & $U^{h} / \alpha$ & $U^{l} /(1-\alpha)$ & $U^{h}+U^{l}$ & $w^{c}$ & $y$ & $N^{s h} / N^{s}$ \\
\hline benchmark & $81.32 \%$ & $9.39 \%$ & $6.89 \%$ & $20.72 \%$ & $11.45 \%$ & 1.16 & 1.44 & $8.26 \%$ \\
\hline$e: 1.00 \rightarrow 1.03$ & +0.01 & -0.01 & -0.12 & -0.28 & -0.17 & $+4.59 \%$ & $+4.71 \%$ & -0.15 \\
\hline$\alpha: 0.67 \rightarrow 0.70$ & -9.41 & -0.78 & -1.04 & -4.88 & -2.61 & $-0.48 \%$ & $+3.47 \%$ & +3.47 \\
\hline$\mu: 0.51 \rightarrow 0.53$ & +9.66 & +0.78 & +1.10 & +8.49 & +3.54 & $+3.38 \%$ & $+0.03 \%$ & -2.63 \\
\hline$y^{c} / y^{s}: 1.00 \rightarrow 1.17$ & +0.00 & -0.00 & -0.03 & -0.08 & -0.05 & $+1.23 \%$ & $+1.26 \%$ & -0.04 \\
\hline$\nu: 0.80 \rightarrow 0.90$ & +0.13 & -0.00 & -0.06 & -0.09 & -0.07 & $+2.59 \%$ & $+2.66 \%$ & -0.11 \\
\hline$\gamma: 2 / 3 \rightarrow 0.70$ & +1.46 & -1.71 & +0.45 & +2.62 & +1.17 & $-0.94 \%$ & $-1.06 \%$ & -0.45 \\
\hline$w^{u}: 0.34 \rightarrow 0.40$ & +2.03 & -0.14 & +0.20 & +0.29 & +0.23 & $+0.20 \%$ & $-0.25 \%$ & +0.06 \\
\hline
\end{tabular}

Table 2: Steady state effects (deviations from the benchmark) of shocks in the model with rigid relative wages

$A$ rise in the proportion of high-skilled workers in the total labor force $(\Delta \alpha>0$, equal to 3 percentage points in table 2$)^{11}$ leads to more output, more crowding-out, and also to a decrease in all unemployment rates. The first two results are somewhat anticipated, and similar to those obtained for instance in Gautier [13]. The last one may look a priori more surprising. It does not depend on the assumption that high-skilled workers employed on simple jobs are more productive than low-skilled workers: assuming identical productivity levels $(\nu=1.00)$ yields similar unemployment rate changes. The result is related both to our representation of the production process and to job competition. Let us first assume away job competition effects and consider perfectly segmented labor markets ${ }^{12}$. It is intuitively clear that an increase (resp. decrease) in the supply of high-skilled (resp. low-skilled) labor will lead to an increase (resp. decrease) in the number of employed workers of that type, although their unemployment rate may increase (resp. decrease). By combining equations (17) and (35), it is readily seen that an increase in high-skilled employment will ceteris paribus increase the marginal productivity of low-skilled workers (in final goods terms). The result will be a lower low-skilled unemployment rate, as in the case of a positive aggregate productivity shock. Similarly, a decrease in low-skilled

\footnotetext{
${ }^{11}$ This amounts to a 14.9 percentage points increase in the ratio of high- to low-skilled labor forces.

${ }^{12}$ We did compute the corresponding numerical simulation.
} 
employment will ceteris paribus decrease the marginal productivity of high-skilled workers (in terms of final goods) and increase the high-skilled unemployment rate, as in the case of a negative aggregate productivity shock. Once we introduce the possibility of job competition, the lower low-skilled unemployment rate and the increased tightness on the simple job market gives to high-skilled workers a stronger incentive to look for a simple job. There is thus more crowdingout. This crowding-out effect is large enough to change the sign of the effect of the population change on the high-skilled unemployment rate. All unemployment rate are thus decreased. We obtain the same (qualitative) result with both rigid and flexible relative wages.

Increasing the relative productivity of high-tech intermediate goods $(\Delta \mu=0.02>0$ in table $2)^{13}$ is a first way of introducing a biased technological change. Combining equations (17) and (35) shows that this change will increase the marginal productivity (in final goods terms) of high-skilled labor, and decrease that of low-skilled labor. Without job competition effects, the high-skilled unemployment rate would decrease and the low-skilled unemployment rate would increase, as in Mortensen-Pissarides [20]. However, when the simple and complex job markets are not perfectly segmented, the decrease in the probability to find a simple job induces highskilled workers to search more intensively on the complex job market. The consequence is a lower crowding-out effect on the simple job market and more congestion on the complex job market. High-skilled workers' search behavior reduces the impact of the relative demand change on the low-skilled unemployment rate, and makes the high-skilled unemployment rate increase rather than decrease (the increase in the number of complex jobs is not large enough to compensate the decrease in the number of high-skilled workers employed on simple jobs). All unemployment rates thus go up as a result of the biased technical change (see table 2). The effect on output is positive, but remains weak when relative wages are rigid (because the wage paid on simple job increases rather than decrease).

Increasing the relative productivity of workers on complex jobs $\left(\Delta\left(y^{c} / y^{s}\right)=+0.17\right.$ in table 2) provides another means of introducing a biased technological change favorable to high-skilled workers. Its effects are however totally different. By combining equations (35) and (17), it

\footnotetext{
${ }^{13}$ This amounts to a 18.8 percentage points increase in the relative productivity coefficient of complex and simple intermediate goods.
} 
is readily seen that it is essentially equivalent to a combination of (positive) high-skilled and (negative) low-skilled labor-augmenting technical progresses. In a Cobb-Douglas framework, labor-augmenting and output-augmenting technical progresses have similar effects. Increasing the relative productivity of workers on complex jobs $\left(\Delta\left(y^{c} / y^{s}\right)>0\right)$ has thus in our setup the same qualitative effects as an aggregate productivity shock $(\Delta e>0)$. This comparison between the two ways of introducing a biased technological change illustrates how much the analysis of job competition and crowding out effects depends on the modelling of the technological constraints. Increasing the relative productivity of low-skilled workers on simple jobs $(\Delta \nu=+0.10$ in table 2) increases total output and wages. As earlier remarks had already suggested, it has a limited impact on search behaviors and crowding-out.

Increasing the low-skilled relative wage $(\Delta \gamma>0$ in table 2) has a strong negative effect on the number of simple jobs. The supply of simple intermediate goods decreases, which affects negatively the demand for capital and for complex goods. All unemployment rates increase, especially the low-skilled one. The decrease in the number of simple jobs induces high-skilled unemployed workers to search more intensively on the complex job market, which slightly reduces the crowding-out effect. Finally, increasing the replacement ratio $\left(\Delta w^{u}>0\right.$ in table 2$)$ has the usual effects of increasing wages and unemployment rates. These effects remain moderate though, at least in this setup with a single representative household and no discouragement effect.

\subsection{Explaining the rise in low-skilled unemployment}

As mentioned before, our model has been calibrated on Belgian data and more or less reproduces the situation observed in 1996. Our objective in this section is to check to what extent the rise in low-skilled unemployment observed after 1975 can be explained by relative labor demand and supply changes. We thus recalculate the equilibrium values of the unemployment rates and the other endogenous variables obtained by changing only two parameters, the proportion of high-skilled workers $\alpha$ and the productivity coefficient of complex intermediate goods $\mu$. This exercise is done under two alternative representations of the wage formation process, rigid vs flexible relative wages. We first compare stationary state equilibrium values and next briefly 
discuss dynamics.

\section{Comparative Statics}

The first two columns of table 3 reproduce the 1996 values of $\alpha, \mu$, and the change observed over the period 1977-1996. These values are taken from Sneessens and Shadman [24]. The measure of the change in $\alpha$ is based on labor force statistics; the measure of the change in $\mu$ is based on the estimation of a Cobb-Douglas production function with three inputs (two types of labor and capital). The net skill bias (NBS in the third column of table 3 ) is a measure of the net relative demand change. It is defined as the ratio of the relative productivity coefficient $(\mu /(1-\mu-\theta))$ and the relative labor force $(\alpha /(1-\alpha))$ of high- and low-skilled workers. In a simple model without vacancy costs and job competition, the difference between the lowand the high-skilled equilibrium unemployment rates would remain unchanged as long as NSB is unchanged; a positive change in NSB increases the difference between the two equilibrium unemployment rates if the relative wage is rigid ${ }^{14}$. From 1977 till 1996, the net skill bias increased by twenty-eight percentage points.

\begin{tabular}{|l|ccc|cccc|}
\hline & $\alpha$ & $\mu$ & $\mathrm{NSB}$ & $U^{h} / \alpha$ & $U^{l} /(1-\alpha)$ & $w^{s l} / w^{c}$ & $\begin{array}{c}\text { crowding } \\
\text { out }\end{array}$ \\
\hline \hline & & & & & & \\
Actual data & & & & & \\
1996 & 0.67 & 0.51 & 1.59 & $6.8 \%$ & $20.1 \%$ & $67 \%$ & n.a. \\
$1977-96$ & +0.45 & +0.33 & +0.28 & +2.1 & +13.3 & +0.0 & n.a. \\
Model with rigid relative wages & & & & \\
$1977-96$ & +0.45 & +0.33 & +0.28 & +2.7 & +10.1 & +0.0 & +6.5 \\
Model with flexible relative wages & & & & +15.5 & +7.2 \\
\hline
\end{tabular}

Table 3: Skill bias, unemployment and relative wages: comparing actual and simulated data

The last four columns of table 3 reproduce the observed and simulated values of the endogenous

\footnotetext{
${ }^{14}$ In a Cobb-Douglas model without vacancy costs and job competition, the relative employment levels are determined by $\frac{\alpha-U^{h}}{1-\alpha-U^{l}}=\frac{\mu}{1-\mu-\theta} \frac{w^{s}}{w^{c}} \Rightarrow \frac{U^{l}}{1-\alpha}-\frac{U^{h}}{\alpha}=\mathrm{NSB} \cdot \frac{w^{s}}{w^{c}}$.
} 
variables of interest: high- and low-skilled unemployment rates, relative wage and crowdingout. The model with rigid relative wages reproduces pretty well the changes observed over the period 1977-96: the high-skilled unemployment rate increases moderately $(+2.7$ percentage points in the simulation, +2.1 in the data), while the low-skilled unemployment rate rises strongly $(+10.1$ in the simulation, +13.3 in the data). In the simulation, the proportion of simple jobs held by high-skilled workers (crowding-out) increases from $1.8 \%$ to $8.3 \%(+6.5)$. This suggests that although the 1996 figure may look rather low in absolute value (compared to estimates based on surveys and a totally different definition of skills), job competition and crowdingout may have contributed substantially to the rise of low-skilled unemployment. Repeating the same simulation experiment but this time eliminating the possibility of job competition (i.e. assuming a perfectly segmented labor market) confirms this conjecture: the change is low-skilled unemployment induced by the net skill bias change is equal to 5 percentage points, compared to 10 in the model with job competition. The two mechanisms, skill bias technological change and crowding-out, may have both contributed significantly to the observed rise in low-skilled unemployment.

The last part of table 3 reproduces the simulation results obtained in the alternative specification with flexible relative wages. The increase in the low-skilled unemployment rate now remains moderate $(+2.4$ percentage points $)$, at the cost though of a $15.5 \%$ decrease in the relative wage of low-skilled workers $\left(w^{s l} / w^{c}\right)$. There is also a slight increase in the high-skilled unemployment rate and a substantial increase in crowding-out. This increased crowding-out may seem strange given the decrease (in both absolute and relative terms) observed in the wage paid on simple jobs. Two effects are at work: the lower wage makes the simple job less attractive, at the same time though it increases the number of jobs and the probability of be hired.

\section{Dynamics}

Up to now we focused on the long term consequences. To illustrate the dynamic adjustment process, we should take into account that these changes in $\alpha$ and $\mu$ were spread over several years. For numerical reasons, we focused on a subperiod corresponding to the years 1980-1993. The changes in the values of $\alpha, \mu$ and the corresponding net skill bias (NSB) over that subperiod are 
reported in table 4. We ran a dynamic simulation assuming (for numerical reasons) that these changes took place progressively and smoothly over eighty quarters ${ }^{15}$, so that the net skill bias evolves as shown in the left panel of figure 2. The right panel of the same figure reproduces the simulated dynamic effects on the difference between the high- and the low-skilled unemployment rates (continuous line, left scale) and on the proportion of simple jobs held by high-skilled workers (dotted line, right scale).

\begin{tabular}{|l|ccc|ccc|}
\hline & $\alpha$ & $\mu$ & $\mathrm{NSB}$ & $U^{h} / \alpha$ & $U^{l} /(1-\alpha)$ & difference \\
\hline \hline \multicolumn{6}{|l|}{ Actual data } \\
1980 & 0.29 & 0.23 & 1.26 & $4.3 \%$ & $8.7 \%$ & 4.4 \\
1993 & 0.61 & 0.48 & 1.59 & $6.6 \%$ & $18.6 \%$ & 12.1 \\
$\begin{array}{l}\text { Simulated data } \\
\text { period 0 }\end{array}$ & 0.29 & 0.23 & 1.26 & $3.7 \%$ & $8.9 \%$ & 5.3 \\
period 80 & 0.61 & 0.48 & 1.59 & $7.0 \%$ & $20.8 \%$ & 13.8 \\
\hline
\end{tabular}

Table 4: Dynamic simulation: initial and final stationary state values, compared to actual data
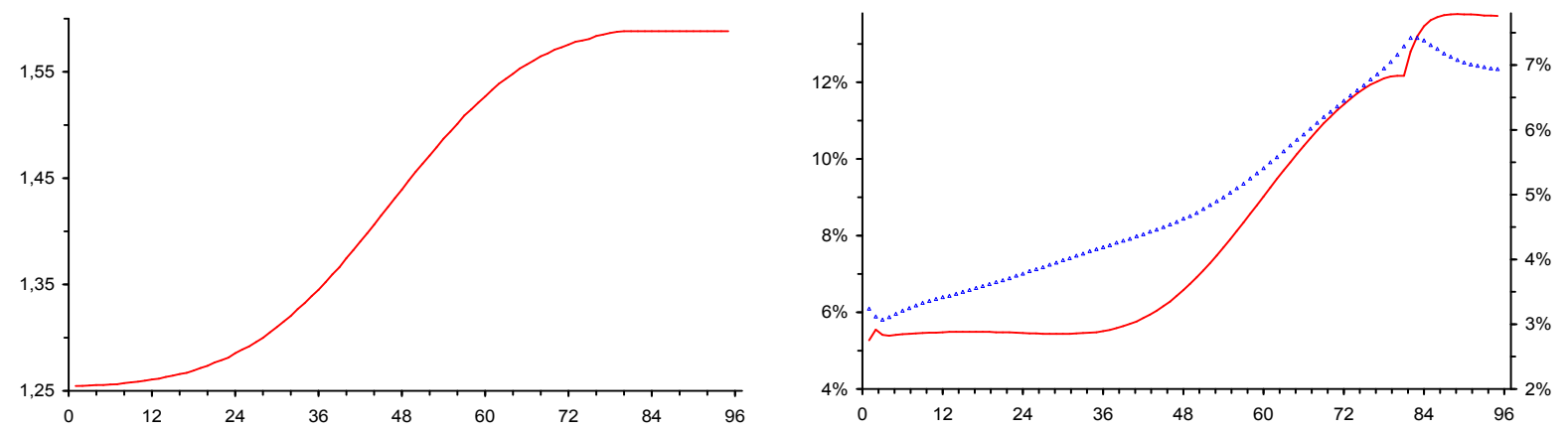

Figure 2: Dynamic simulation with rigid relative wages: exogenous net skill bias change (left panel), induced changes in the difference between the high- and the low-skilled unemployment rates (right panel, continuous line, left scale) and in crowding-out (dotted line, right scale)

The dynamic adjustment process can best be described by distinguishing two phases of equal length. During the first forty periods, the low- and the high-skilled unemployment rate increase at the same pace, so that the difference between the two remains unchanged. The rise in the high-skilled unemployment rate, despite a favorable net technological bias, is due to matching

\footnotetext{
${ }^{15}$ This dynamic simulation should thus not be interpreted as a historical simulation. All simulations are done with the Dynare software developed at Cepremap, Paris
} 
difficulties and the time it takes to fill new complex job vacancies. High-skilled workers reduce their unemployment risk by competing more actively with low-skilled workers on the simple job market (crowding-out effect). After period 40, the high-skilled unemployment rate progressively stabilizes and next starts declining until it reaches its new stationary state value; the lowskilled unemployment rate goes on increasing for a few more periods and next stabilizes at its new stationary state value. The difference between the two unemployment rates becomes progressively larger; there is more and more crowding-out, until the new stationary state is reached.

\section{Concluding remarks}

Our objective in this paper was to examine the consequences of biased technological and labor force composition changes on the unemployment rate of low- and high-skill groups. We constructed for that purpose a dynamic general equilibrium model with two types of jobs and two types of workers, and with endogenous job competition and crowding-out effects. The model was calibrated on Belgian data ( a country which in terms of wage and unemployment changes is quite representative of the EU average) and simulated to evaluate the quantitative importance of net skill bias effects over the last decades. Let us emphasize the following three results:

- our numerical simulations suggest that, when labor market institutions are such that relative wages are rigid (as in many EU countries), most of the unemployment rate changes observed between the late seventies and the mid nineties (moderate increase in the highskilled unemployment rate, huge increase in the low skilled unemployment rate) can be explained by simply changing two exogenous parameters, technological bias and labor force composition;

- search behaviors and job competition effects seem to play a crucial role; our numerical simulations suggest that they may have considerably amplified the effects of the bias technological change on the low-skilled unemployment rate; this result is obtained although the model generates a fairly low proportion of "over-qualified" workers $(8.3 \%$, while recent estimates reported in the literature vary from 10 to $30 \%$ ); 
- the modelling of the production sector plays a crucial role; by distinguishing final and intermediate goods sectors, we avoid the assumption of perfect substitutability between low- and high-skilled labor implicit in many search equilibrium models and obtain a specification similar to the one traditionally used in RBC models.

Many questions have of course not been addressed. The model should be further developed for instance to explain rather than assume the wage rigidity, or to endogenize the job destruction rate. Economic policy implications should also be investigated. We leave these questions for future research. 


\section{References}

[1] Acemoglu, D. (1998), "Why do new technologies complement skills ? Directed technical change and wage inequality", Quarterly Journal of Economics, 113 (4), 1055-1089.

[2] Acemoglu, D. (1999), "Changes in unemployment and wage inequality: An alternative theory and some evidence", American Economic Review, 89 (5), 1259-1278.

[3] Albrecht, J. and S. Vroman, "A matching Model with Endogenous Skill Requirements", International Economic Review, 43 (2002), 283-305.

[4] Andolfatto, D., "Business Cycles and Labor-Market Search", American Economic Review 86-1 (1996) $112-132$.

[5] Autor D.H., L.F. Katz and A.B. Krueger, "Computing inequality: Have computers changed the labor market?", Quarterly Journal of Economics, 113 (1998), 1169-1213.

[6] Beaudry, P. et D. Green (1998), "What is driving U.S. and Canadian wages : Exogeneous technological change or endogeneous choice of technique", Working paper n6853, National Bureau of Economic Research.

[7] Berman E., J. Bound and S. Machin, "Implications of skill-biased technological change: international evidence", Quarterly Journal of Economics, 113 (1998), 1245-1279.

[8] Cahuc, P and A. Zylberberg, Le Marché du Travail, Bruxelles: De Boeck Université, 2001.

[9] Cockx, B. and M. Dejemeppe, "Do the Higher Educated Unemployed Crowd out the Lower Educated Ones in a Competition for Jobs?", IZA DP 541, 2002.

[10] Collard, F., R. Fonseca and R. Munoz, "Spanish Unemployment Persistence and the Ladder Effect", 2001, mimeo, IRES, Université catholique de Louvain.

[11] Dolado, J., F. Felgueroso and J. Jimeno, "Youth labor markets in Spain: Education, training and crowding-out", European Economic Review, 44 (2000) 943-956.

[12] Dolado, J., M. Jansen et J. Jimeno, "A Matching Model of Crowding-Out and On-the-Job Search (with an Application to Spain)", 2002, CEPR DP3466.

[13] Gautier, P.A., "Unemployment and Search Externalities in a Model with Heterogeneous Jobs and Heterogeneous Workers", Economica, 69 (2002) 21-40.

[14] Gautier, P.A., G.J. van den Berg, J.C. van Ours and G. Ridder "Worker turnover at the firm level and crowding out of lower educated workers", European Economic Review, 46 (2002) 523-538. 
[15] Hartog, J., "Over-education and earnings: where are we, where should we go?", Economics of Education Review, 19 (2000), 131-147.

[16] Machin, S. and J. Van Reenen, "Technology and changes in skill structure: Evidence from seven OECD countries", Quarterly Journal of Economics, 113 (1998), 1215-1244.

[17] Manacorda, M., and B. Petrongolo, "Skill Mismatch and Unemployment in OECD countries", Economica, 66 (1999) 181-207.

[18] Marimon, R., and F. Zilbotti, "Unemployment vs mismatch of talents: Reconsidering unemployment benefits", The Economic Journal, 109/455 (1999) 266-291 .

[19] Merz, M., "Search in the labor market and the real business cycle", Journal of Monetary Economics, 36 (1995) 269-300.

[20] Mortensen D.T., and C.A. Pissarides, "Unemployment Responses to Skill-Biased Shocks: The Role of Labor Market Policy", The Economic Journal, 109/455(1999) 242-265.

[21] OECD, Employment Outlook, Chapter 3, July 1996.

[22] ONSS, Rapport annuel, Bruxelles:Office National de sécurité Sociale.

[23] Pissarides, C., Equilibrium Unemployment Theory, Oxford:Basil Blackwell, 1990.

[24] Sneessens, H. and F. Shadman, "Analyse macro-économique des effets de réductions ciblées des charges sociales", Revue belge de sécurité sociale, 3 (2000) 613-630.

[25] Delmotte J., G. Van Hootegem and J. Dejonckheere, "Les entreprises et le recrutement en Belgique en 2000, 2001", HIVA, Katholieke Universiteit Leuven, and UPEDI.

[26] Van der Linden, B. and E. Dor, "Labor market policies and equilibrium employment: Theory and application for Belgium", IRES Discussion Paper 2001-05, Université catholique de Louvain. 


\section{IZA Discussion Papers}

\begin{tabular}{|c|c|c|c|c|}
\hline No. & Author(s) & Title & Area & Date \\
\hline 769 & $\begin{array}{l}\text { L. Flood } \\
\text { J. Hansen } \\
\text { R. Wahlberg }\end{array}$ & $\begin{array}{l}\text { Household Labor Supply and Welfare } \\
\text { Participation in Sweden }\end{array}$ & 3 & $04 / 03$ \\
\hline 770 & A. Heitmueller & Coordination Failures in Network Migration & 1 & $04 / 03$ \\
\hline 771 & $\begin{array}{l}\text { A. Calvó-Armengol } \\
\text { Y. Zenou }\end{array}$ & $\begin{array}{l}\text { Job Matching, Social Network and } \\
\text { Word-of-Mouth Communication }\end{array}$ & 5 & $05 / 03$ \\
\hline 772 & $\begin{array}{l}\text { E. Patacchini } \\
\text { Y. Zenou }\end{array}$ & $\begin{array}{l}\text { Search Intensity, Cost of Living and Local } \\
\text { Labor Markets in Britain }\end{array}$ & 3 & $05 / 03$ \\
\hline 773 & A. Heitmueller & $\begin{array}{l}\text { Job Mobility in Britain: Are the Scots Different? } \\
\text { Evidence from the BHPS }\end{array}$ & 1 & $05 / 03$ \\
\hline 774 & $\begin{array}{l}\text { A. Constant } \\
\text { D. S. Massey }\end{array}$ & $\begin{array}{l}\text { Labor Market Segmentation and the Earnings of } \\
\text { German Guestworkers }\end{array}$ & 1 & $05 / 03$ \\
\hline 775 & $\begin{array}{l}\text { J. J. Heckman } \\
\text { L. J. Lochner } \\
\text { P. E. Todd }\end{array}$ & Fifty Years of Mincer Earnings Regressions & 5 & $05 / 03$ \\
\hline 776 & $\begin{array}{l}\text { L. Arranz-Aperte } \\
\text { A. Heshmati }\end{array}$ & $\begin{array}{l}\text { Determinants of Profit Sharing in the Finnish } \\
\text { Corporate Sector }\end{array}$ & 2 & $05 / 03$ \\
\hline 777 & $\begin{array}{l}\text { A. Falk } \\
\text { M. Kosfeld }\end{array}$ & $\begin{array}{l}\text { It's all about Connections: Evidence on Network } \\
\text { Formation }\end{array}$ & 6 & $05 / 03$ \\
\hline 778 & F. Galindo-Rueda & $\begin{array}{l}\text { Employer Learning and Schooling-Related } \\
\text { Statistical Discrimination in Britain }\end{array}$ & 5 & 05/03 \\
\hline 779 & M. Biewen & $\begin{array}{l}\text { Who Are the Chronic Poor? Evidence on the } \\
\text { Extent and the Composition of Chronic Poverty } \\
\text { in Germany }\end{array}$ & 1 & $05 / 03$ \\
\hline 780 & $\begin{array}{l}\text { A. Engellandt } \\
\text { R. T. Riphahn }\end{array}$ & Temporary Contracts and Employee Effort & 1 & $05 / 03$ \\
\hline 781 & $\begin{array}{l}\text { J. H. Abbring } \\
\text { J.R. Campbell }\end{array}$ & $\begin{array}{l}\text { A Structural Empirical Model of Firm Growth, } \\
\text { Learning, and Survival }\end{array}$ & 5 & $05 / 03$ \\
\hline 782 & $\begin{array}{l}\text { M. Güell } \\
\text { B. Petrongolo }\end{array}$ & $\begin{array}{l}\text { How Binding Are Legal Limits? Transitions from } \\
\text { Temporary to Permanent Work in Spain }\end{array}$ & 1 & $05 / 03$ \\
\hline 783 & $\begin{array}{l}\text { B. T. Hirsch } \\
\text { E. J. Schumacher }\end{array}$ & $\begin{array}{l}\text { Match Bias in Wage Gap Estimates Due to } \\
\text { Earnings Imputation }\end{array}$ & 5 & $05 / 03$ \\
\hline 784 & $\begin{array}{l}\text { O. Pierrard } \\
\text { H. R. Sneessens }\end{array}$ & $\begin{array}{l}\text { Low-Skilled Unemployment, Biased } \\
\text { Technological Shocks and Job Competition }\end{array}$ & 2 & $05 / 03$ \\
\hline
\end{tabular}

An updated list of IZA Discussion Papers is available on the center's homepage www.iza.org. 